\title{
CORRECTION
}

Cite this: Phys. Chem. Chem. Phys., 2015, 17, 20425

\section{Correction: A novel benzoxazine/cyanate ester blend with sea-island phase structures}

\author{
Xiaodan Li, ${ }^{\text {ab }}$ Xiaoyong Luo ${ }^{\mathrm{b}}$ and Yi Gu${ }^{\star b}$
}

Correction for 'A novel benzoxazine/cyanate ester blend with sea-island phase structures' by Xiaodan Li et al., DOI: $10.1039 / \mathrm{c} 5 \mathrm{cp} 90128 \mathrm{f}$

Phys. Chem. Chem. Phys., 2015, DOI: 10.1039/c5cp02426a.

www.rsc.org/pccp

The scale bar shown in the SEM picures of Fig. 1 is incorrect and should read $10 \mu \mathrm{m}$ instead of $10 \mathrm{~m}$. The amended version of Fig. 1 is shown below:
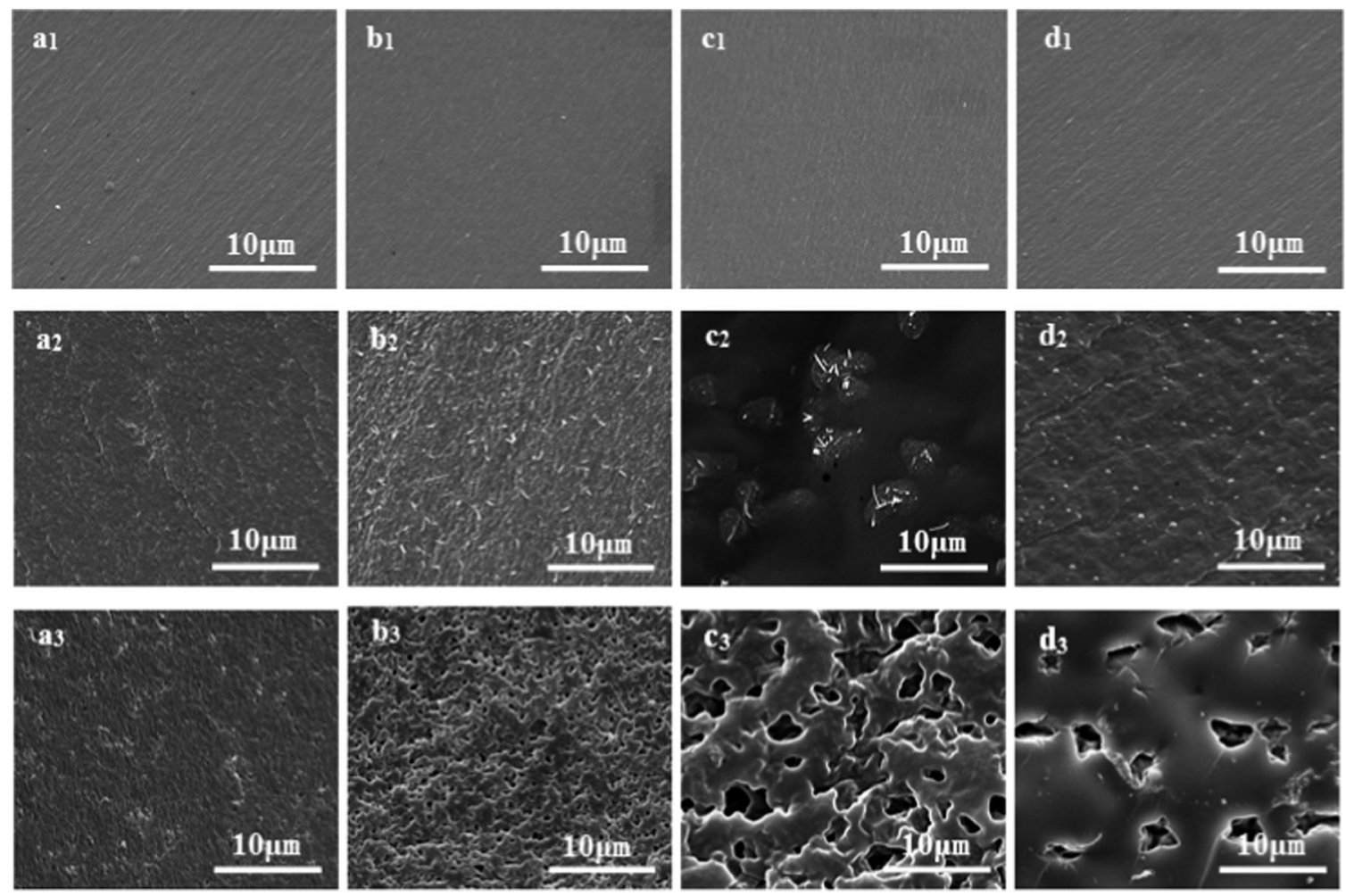

Fig. 1 SEM phase morphology of C-BOZ/BADCy blends: the uncured, cured at $120{ }^{\circ} \mathrm{C}$ for $10 \mathrm{~h}$ and etched in acetone for $0.5 \mathrm{~h}$ of the $5 / 5$ blend $\left(a_{1}, a_{2}\right.$ and $\left.a_{3}\right)$, the $7 / 3$ blend $\left(b_{1}, b_{2}\right.$ and $\left.b_{3}\right)$, the $8 / 2$ blend $\left(c_{1}, c_{2}\right.$ and $\left.c_{3}\right)$ and the $9 / 1$ blend $\left(d_{1}, d_{2}\right.$ and $\left.d_{3}\right)$.

The Royal Society of Chemistry apologises for these errors and any consequent inconvenience to authors and readers.

\footnotetext{
${ }^{a}$ Key Laboratory of Catalysis Science and Technology of Chongqing Education Commission, College of Environment and Biological Engineering, Chongqing Technology and Business University, Chongqing, 400067, P. R. China

${ }^{b}$ State Key Laboratory of Polymer Materials Engineering, College of Polymer Sciences and Engineering, Sichuan University, Chengdu 610065, Sichuan, P. R. China. E-mail:12345ruby@163.com,guyi@scu.edu.cn
} 